\title{
High consumption of ultra-processed food may double the risk of subclinical coronary atherosclerosis: the Aragon Workers' Health Study (AWHS)
}

Henry Montero-Salazar ${ }^{1}$, Carolina Donat-Vargas ${ }^{1,2,3,4,5^{*}}$ (D, Belén Moreno-Franco ${ }^{6,7,8}$, Helena Sandoval-Insausti ${ }^{1,9}$, Fernando Civeira ${ }^{6,7,10}$, Martín Laclaustra ${ }^{6,7,10}$ and Pilar Guallar-Castillón ${ }^{1,3,4,5}$

\begin{abstract}
Background: Ultra-processed food (UPF) consumption, which is increasing worldwide, has recently been associated with an increased risk of death and cardiovascular disease. We aimed to assess whether consumption of UPF is directly associated with subclinical coronary atherosclerosis in middle-aged men.

Methods: A computed tomography scan was performed on 1876 men from the Aragon Workers' Health Study, recruited from January 2011 to December 2014, to assess coronary calcium. All participants were free of coronary heart disease. Dietary intake was collected by a validated 136-item semi-quantitative food frequency questionnaire. UPF was defined according to the NOVA classification. Associations between consumption of total energy-adjusted UPF and Coronary Calcium Agatston Score (CACS) — categorized into CACS of $0,>0$ and $<100$, and $\geq 100$ —were cross-sectionally assessed by generalized ordered logistic regression adjusted for main confounders.

Results: No coronary calcium was detected in $60.2 \%$ of the participants, whereas $10.2 \%$ had a CACS $\geq 100$. A significant dose-response association was observed between energy-adjusted UPF consumption and the risk of having a CACS $\geq 100$, when compared with those in the lowest CACS categories (CACS of 0 together with CACS > 0 and $<100)$. The fully adjusted ORs $(95 \% \mathrm{Cl})$ of having a CACS $\geq 100$ across quartiles of energy-adjusted UPF consumption (approximately $100 \mathrm{~g} /$ day in the lowest quartile (ref.) and $500 \mathrm{~g} /$ day in the highest) were 1.00 (ref.), $1.50(0.93,2.42), 1.56(0.96,2.52)$, and $2.00(1.26,3.16), p$ trend .005 .

Conclusion: In this middle-aged worker's sample, approximately $500 \mathrm{~g} /$ day of UPF consumption was associated with a 2-fold greater prevalence of subclinical coronary atherosclerosis than consuming only $100 \mathrm{~g} /$ day, independently of total energy intake and other well-established cardiovascular risk factors.
\end{abstract}

Keywords: Ultra-processed food, Subclinical coronary atherosclerosis, Coronary calcium, Cross-sectional cohort study, Nutritional epidemiology

\footnotetext{
* Correspondence: Carolina.donat.vargas@ki.se

${ }^{1}$ Department of Preventive Medicine and Public Health, School of Medicine,

Universidad Autónoma de Madrid, CEI UAM+CSIC, Avda. Arzobispo Morcillo,

n 4, 28029 Madrid, Spain

${ }^{2}$ Unit of Nutritional and Cardiovascular Epidemiology, Environmental

Medicine Institute (IMM), Karolinska Institutet, Stockholm, Sweden

Full list of author information is available at the end of the article
}

(C) The Author(s). 2020 Open Access This article is licensed under a Creative Commons Attribution 4.0 International License, which permits use, sharing, adaptation, distribution and reproduction in any medium or format, as long as you give appropriate credit to the original author(s) and the source, provide a link to the Creative Commons licence, and indicate if changes were made. The images or other third party material in this article are included in the article's Creative Commons licence, unless indicated otherwise in a credit line to the material. If material is not included in the article's Creative Commons licence and your intended use is not permitted by statutory regulation or exceeds the permitted use, you will need to obtain permission directly from the copyright holder. To view a copy of this licence, visit http://creativecommons.org/licenses/by/4.0/. The Creative Commons Public Domain Dedication waiver (http://creativecommons.org/publicdomain/zero/1.0/) applies to the data made available in this article, unless otherwise stated in a credit line to the data. 


\section{Background}

The food and beverage industry has experienced high growth in recent years, and the consumption of ultraprocessed food (UPF) has substantially increased, fostered by attractive packaging and intensive marketing [1]. UPF consumption in Spain is low to moderate [2], but it is increasing rapidly. While in 1990, UPF consumption represented $11 \%$ of daily energy intake in Spain, it has almost tripled in 10 years [3]. In 2000, the mean contribution of UPF in total energy intake was about $35 \%$ in Spain and Italy, but it reached up to $60 \%$ in the Netherlands, Sweden, Norway, Denmark, and the UK general population [4].

UPF is formulated mostly or entirely from substances derived from food together with additives, with little, if any, intact food. Processing entails greater durability, tastier flavors, and readiness to consume at a very low price. UPF is characterized by poor nutritional value and high energy density with low fiber and micronutrient content, as well as high amounts of sodium, saturated and trans fats, and simple sugars $[5,6]$. On the one hand, all aforementioned detrimental nutrients have been individually associated with subclinical atherosclerosis and cardiovascular disease (CVD) [7-9]. On the other hand, UPF also contains a great diversity of additives, many of which have shown adverse effects on the vascular system in experimental studies [10-12]. In particular, the additive phosphate, present in almost all UPF, is involved in atherosclerosis by inducing vascular calcification both in vitro and in vivo [13]. Finally, UPF consumption replaces the intake of other unprocessed or minimally processed food and freshly prepared meals that have beneficial nutritional attributes, also affecting health in an indirect way.

Recently, in the large prospective NutriNet-Santé cohort, an absolute increment of $10 \%$ of UPF in the diet has been associated with a $12 \%, 13 \%$, and $11 \%$ statistically significant increase in the rates of overall CVD, coronary heart disease (CHD), and cerebrovascular disease, respectively [14]. Likewise, consumption of UPF has been associated with cardiometabolic conditions [15], such as overweight or obesity [16], hypertension [17], dyslipidemia [18], and diabetes [19], as well as with CVD mortality or total mortality [2, 20, 21].

Atherosclerosis, which underlies CVD, is a complex disease in which fat, inflammation cells, scar tissue, and deposits of calcium accumulate within the walls of the arteries [22]. The presence of calcium in the coronary arteries is an indicator of subclinical atherosclerotic disease and a marker of coronary damage [23], as well as a strong and independent predictor of future coronary heart disease [24, 25]. Current guidelines endorse the measurement of coronary calcium to improve risk prediction of coronary disease in selected asymptomatic individuals [26, 27]. Accordingly, high calcium in coronary arteries has been consistently associated with general coronary disease [28], myocardial infarction [28, 29], heart failure [29], and stroke [30].

To date, no epidemiological study has yet evaluated the direct impact of UPF consumption on the coronary arteries in asymptomatic subjects. The aim of this study is therefore to examine the association between UPF consumption and subclinical coronary atherosclerosis in a sample of middle-aged subjects with a low prevalence of clinical comorbidities.

\section{Methods}

\section{Study design and population}

The present cross-sectional study includes a sample of participants from the Aragon Workers' Health Study (AWHS), the design of which has been described in detail elsewhere [31, 32]. Study participants are workers of Opel Spain automobile assembly plant located in Figueruelas (Zaragoza, Spain) that were recruited during a standardized clinical exam in 2009-2010 (participation rate 95.6\%). In addition, between January 2011 and December 2014, all participants who were aged 40-60 years old (34\% of initial participants) were invited to undergo a coronary calcification scan and provided blood and urine samples for the study biobank, as well as to answer a comprehensive questionnaire on cardiovascular and lifestyle factors, including diet. No relevant differences were detected in baseline characteristics between total participants and those who undergo the coronary calcification scan. Among the 2617 workers (all Caucasian) recruited into the AWHS imaging study, 2128 had complete quantification of coronary calcification. Likewise, those subjects with previous history of CVD $(n=28)$, women $(n=97)$, and those with an extreme total energy intake $(<600$ or $>4200 \mathrm{kcal})$ $(n=127)$ were excluded, resulting in a final sample of 1876 participants (Fig. 1).

\section{Data collection}

Demographic information including age, sex, marital status, educational level, smoking, sleep duration (both on weekdays and weekends), and diabetic status was obtained by questionnaires. Also, leisure-time physical activity and time spent in sedentary activities were assessed using a formerly validated questionnaire, i.e., the Health Professionals' Follow-up physical activity questionnaire [33], that was highly correlated with objective measurements using triaxial accelerometer (RT3 Triaxial Research Tracker) as reference (Spearman's correlation coefficient of $0.51 ; p<$ 0.001). Participants were asked about the time devoted to 


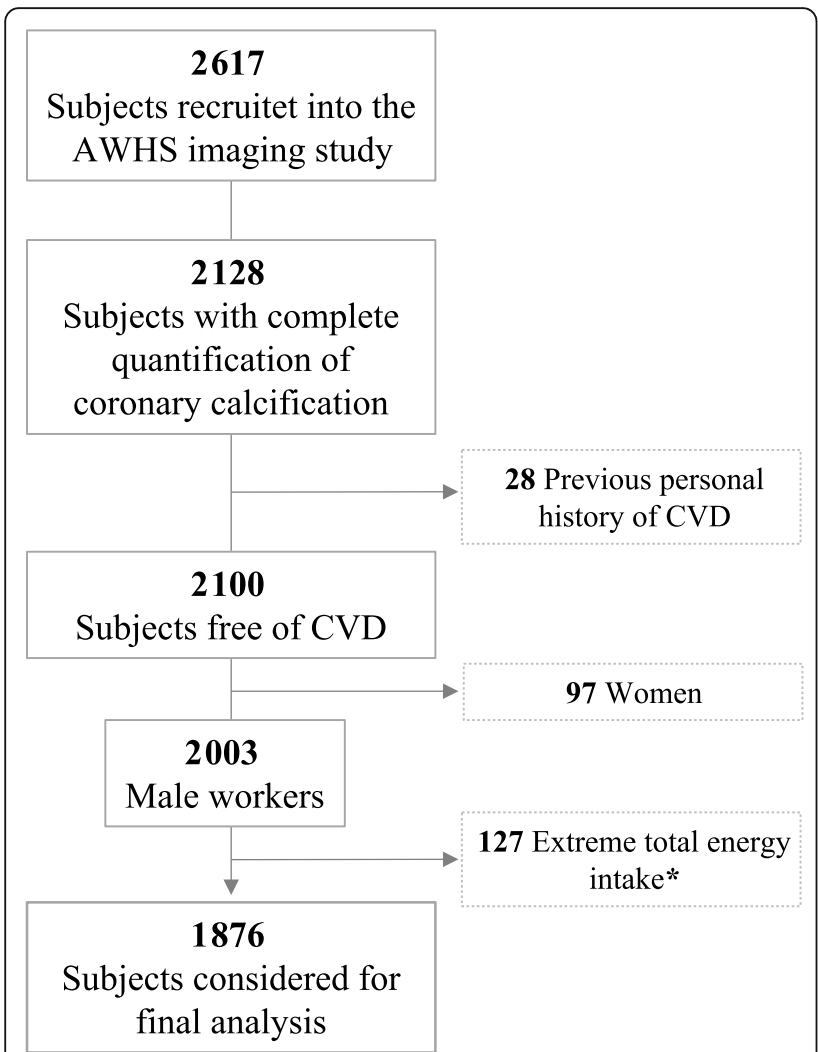

Fig. 1 Flow chart for the study association: Coronary Artery Calcium Score and ultra-processed food consumption. *Total energy intake of $<600$ or $>4200 \mathrm{kcal}$ in men was considered extreme values. Subjects recruited in the imaging AWHS. AWHS, Aragon Workers' Health Study; CVD, cardiovascular disease

17 different activities during the preceding year, and leisure-time physical activity was expressed in metabolic equivalents (METs)-h/week.

Serum samples were obtained, and cholesterol, triglycerides, and glycemia were measured. Study participants went through a standardized clinical exam with blood pressure (BP) and heart rate measurements. BP was measured three consecutive times using an automatic oscillometric sphygmomanometer after being seated for $5 \mathrm{~min}$. Anthropometrics, including height, weight, and waist circumference, were also measured following standardized procedures, and body mass index (BMI, in $\mathrm{kg} / \mathrm{m}^{2}$ ) was calculated.

Physicians and nurses collecting these data underwent specific training and standardization programs organized by the study investigators. Compliance with study procedures was routinely monitored, and deviations were corrected. The study conforms to the ISO9001-2008 quality standard.

\section{Dietary assessment and ultra-processed food consumption}

Their usual diet over the preceding year was assessed using a 136-item semi-quantitative food frequency questionnaire (FFQ) previously validated and repeatedly re-evaluated in Spain [34-36]. This FFQ considers seasonal variations and differences in food consumption between weekdays and weekend patterns. We measured the frequency of food consumption in nine categories (ranging from never or almost never to more than six servings per day), also including a standard portion size for each food item. To estimate daily consumption for each food item, we multiplied the portion size by the frequency of consumption.

We listed all food and beverage items of the FFQ according to NOVA classification [6] which organizes food into four groups based on the scope and purpose of industrial processing. The first group includes unprocessed or minimally processed food, which is fresh or modified by filtering, freezing, drying, or pasteurization, with no addition of salt, sugar, oils, or fats. The second group contains processed culinary ingredients. These are substances derived from nature, but have undergone processes such as pressing, refining, or milling and might contain additives to preserve the original properties (i.e., salt, sugar, honey, vegetable oils, butter, lard, and vinegar). The third group comprises processed food. This is food which has undergone preservation or preparation methods (e.g., smoking, curing, or fermentation) in order to last longer or to enhance their sensory qualities. Examples include canned or bottled vegetables and legumes, fruit in syrup, canned fish, cheese, freshly made bread, and salted/sugared nuts and seeds. The fourth group comprises ultra-processed food and drink products that are made predominantly or entirely from industrial substances and contain little or no whole food. Under this classification, we can find products such as hamburgers, frozen pizza and pasta dishes, French fries, breads, cakes, industrially manufactured biscuits (cookies), jams and confectionery, margarines, cereal bars, soft drinks and other sugary beverages such as sugared milk and fruit drinks, fruit yogurts, instant packaged soups and noodles, and sweet or savory snacks.

For each participant, total UPF consumption in grams per day (g/day) was calculated summing up the consumption from each UPF item included in the fourth group of the NOVA classification (Additional File 1: Table S1). The grams per day of UPF were adjusted for total energy intake by the residual method [37].

\section{Outcome assessment: Coronary Agatston Calcium Score}

Coronary calcium quantification was performed using non-contrast ECG-gated prospective acquisition by a 16multidetector computed tomography scanner (Philips). Agatston's method is a summed score of all coronary calcified lesions, accounting for both the total area and the maximum density of coronary calcium. A high Coronary Calcium Agatston Score (CACS) is a strong 
indicator of extensive disease with a significant amount of calcium deposits. CACS remains the reference standard and the most commonly used coronary artery calcium score in clinical practice [38].

CACS was divided into three consecutive categories: 0 , $>0$ and $<100$, and $\geq 100$. Having a CACS $>0$ represents the presence of calcium, and surpassing a threshold of $\geq$ 100 is considered as having a moderate to severe subclinical coronary atherosclerosis and has been associated with increases in coronary heart disease rates [39].

\section{Statistical analysis}

Participants were categorized into quartiles of daily grams of UPF consumption after adjusting for total energy intake using the residual method [37]. The analyses were also carried out using quartiles of daily percentage of energy derived from UPF, revealing very similar results (data not presented).

The adequacy of the proportional odds assumption across response categories (a requirement for conducting ordered logistic regression) was examined by using tests for proportionality (Wald's test and Brant's test). We found a violation of this assumption ( $p$ values < 0.05). Accordingly, we estimated the odds ratio (OR) and corresponding 95\% confidence intervals (CI) for having progressed to categories of more coronary artery calcium using generalized ordered logistic models (gologit/partial proportional odds model). These models are less restrictive than the proportional-odds/parallel-lines models and do not assume the equality of slopes among categories. This approach yields two ORs, one describing the relationship between the lowest vs. the two highest categories of the response variable (CACS), and the other describing the relationship between the two lowest categories vs. the highest one [40].

We additionally performed a standard binary logistic regression for the collapsed categories to estimate the OR for CACS $>0$ (compared with CACS of 0 ) and for CACS $\geq 100$ (compared with CACS $<100$ ), to provide estimations which can easily be understood as they are widely used. So, we provide two estimators to describe the association between UPF consumption and CACS. To calculate the $p$ for linear trend, the mean concentrations of UPF in each quartile were used and treated as a continuous variable in the model. Likewise, the standard binary logistic regression was used to perform restricted cubic splines with 3 knots (at the 10th, 50th, and 90th percentiles of the distribution) to visualize flexible doseresponse associations.

We used three models with progressive adjustment for covariates that can operate as confounders [41]. Model 1 was adjusted for age (continuous, years); model 2 was further adjusted for demographic and lifestyle factors: marital status (married, not married), education (middle school, high school, professional training, and college), smoking status (never, former, and current smoker), physical activity (in MET-h/week), time spent sleeping during the weekdays (number of hours of sleep, continuous), time spent sleeping during the weekend (number of hours of sleep, continuous), and dietary factors such as alcohol consumption (g/day), total fiber (g/day), cholesterol intake,(mg/day), and total energy intake (kcal); and model 3 was further adjusted for cardiometabolic risk factors: total cholesterol in blood $(\mathrm{mg} / \mathrm{dL})$, HDL cholesterol in blood $(\mathrm{mg} / \mathrm{dL})$, systolic and diastolic blood pressure $(\mathrm{mmHg})$, BMI $\left(<25,25\right.$ to $\left.<30, \geq 30 \mathrm{~kg} / \mathrm{m}^{2}\right)$, and diabetes (yes, no).

To maximize the use of available information, missing values on education $(<1 \%)$ and smoking $(<1 \%)$ were included in a separate category. Missing values on hours of sleep during the week $(<1 \%)$ and BMI $(<1 \%)$ were imputed by predicted values from a multivariable regression model containing the corresponding explanatory variables. Missing values on diabetes (3\%) were considered as having a non-disease status.

We tested for interactions between UPF consumption and age, BMI, smoking status, alcohol consumption, and physical activity, on the multiplicative scale using the likelihood ratio test, comparing binary logistic models with and without an interaction term.

Analyses were performed with Stata/SE, version 15.1 (StataCorp, College Station). Statistical significance was set at the two-sided 0.05 level.

\section{Results}

All participants were Caucasian males with a mean age of $51 \pm 3.7$ years. The average UPF consumption ranged from $117 \pm 56 \mathrm{~g} /$ day in the lowest quartile to $484 \pm 217$ $\mathrm{g} /$ day in the highest one. Those in the highest quartile of UPF consumption were less frequently current smokers; performed less physical activity; had a lower consumption of alcohol, fiber, micronutrients (vitamins and minerals); and had lower HDL cholesterol levels. Likewise, although non-statistically significant, those consuming more UPF were more frequently obese than those consuming less. In general, no other meaningful differences in demographic and lifestyle variables were observed across UPF quartiles (Table 1).

Regarding CACS, $60.2 \%$ of the participants $(n=1129)$ had no coronary artery calcium, $29.6 \%$ had a CACS $>0$ but $<100(n=556)$, and the remaining $10.2 \%(n=191)$ had a CACS $\geq 100$ (those with a well-defined and established disease). A significant dose-response association was observed between daily consumption of UPF and the risk of progress from the two lowest categories (CACS of 0 together with CACS $>0$ and $<100$ ) to the highest category (CACS $\geq 100$ ). The fully adjusted ORs $(95 \% \mathrm{CI})$ of having a CACS $\geq 100$ across quartiles of 
UPF consumption (1st quartile as reference) were 1.50 (0.93, 2.42), $1.56(0.96,2.52)$, and 2.00 (1.26, 3.16), $p$ trend .005 . However, there was no association between consumption of UPF and the risk of progressing from no coronary artery calcium (CACS of 0 ) to the two highest CACS categories (CACS $>0$ and $<100$ together with CACS $\geq 100$ ) (Table 2).

Similar results were observed when performing the standard binary logistic regression to estimate OR for CACS $>0$ (with CACS of 0 as reference) and for CACS $\geq 100$ (with CACS $<100$ as reference) (Additional File 1: Table S2). Thus, a clear dose-response relationship between UPF consumption and coronary artery calcium was only appreciated for CACS $\geq 100$ compared to those with CACS $<100$ (Fig. 2).

No interactions were detected between UPF consumption and age $(p=0.68)$, BMI $(p=0.25)$, smoking status $(p=0.15)$, alcohol consumption $(p=0.31)$, and physical activity $(p=0.61)$.

\section{Discussion}

This is the first epidemiological study assessing the association between UPF consumption and early subclinical atherosclerosis. In this sample of middle-aged male workers, those with the highest consumption of UPF (on average approximately $500 \mathrm{~g} /$ day) compared with those with the lowest consumption (on average approximately $100 \mathrm{~g} /$ day) have a 2-fold increased risk of having a subclinical coronary atherosclerosis outlined by a CACS $\geq$ 100. This association was independent of the main cardiometabolic risk factors (cholesterol level, blood pressure, BMI, and diabetes), as well as dietary and lifestyle factors. Results were robust and remained similar using different methodological approaches. When we categorized the coronary calcium as CACS $\leq 0$ vs. CACS $>0$, we classified as having a "positive outcome"/"positive in atherosclerosis" a very heterogeneous group of participants with mixing characteristics, including those with CACS very close to 0 and those with mild, moderate, and even severe subclinical coronary atherosclerosis. This lack of specification and the fact that subjects with very small and incipient lesions (and in some cases with the coronary calcium almost expected by age) are classified as "positive outcome"/"positive in atherosclerosis" may be the reason for not having found an association when comparing $\mathrm{CACS}>0$ vs. $\mathrm{CACS} \leq 0$. In contrast, in the second categorization (CACS $<100$ vs. CACS $\geq 100$ ), by establishing the cutoff point at a CACS equal to 100 , we classified as "positive outcome"/"positive in atherosclerosis" those with a well-defined and more established disease.

Scientific evidence has placed fresh fruit, vegetables, whole grains, nuts, legumes, and olive oil-for their high content of fiber and micronutrients with antioxidant and anti-inflammatory properties-as the most protective foods for the cardiovascular system [42, 43]. Despite all this knowledge, during the last decade, there has been a worldwide rapid increase in the consumption of UPF, in which these healthy components are scarce, due to the prevailing fact that UPF is easily accessible, tasty, and cheap [44].

Of particular concern is that (i) UPF is highly energy dense and is usually consumed in large portion sizes; (ii) UPF contains excessive salt, saturated fat, and refined sugars, while lacking fiber and micronutrients such as vitamins and antioxidants; (iii) additionally, potentially harmful compounds may be added or generated during UPF processing (such as colorants, additives, acrylamide, trans-fatty acids (TFAs)). Several of these UPF characteristics are known risk factors for cardiometabolic conditions [15], as we explain next.

To begin with, dense food and sugar-sweetened beverages might delay the trigger of the internal satiety signal, leading to excessive caloric ingestion [45]. Excessive intake of energy, fat, and sugar contributes to weight gain and increases the risk of obesity [16], which is a major risk factor for CVD. However, the associations observed in this study between consumption of UPF and subclinical coronary atherosclerosis were statistically significant even after adjusting for BMI. Thus, BMI does not fully explain the association between UPF and subclinical atherosclerosis.

Most of the salt intake in high-income nations comes from UPF. Among them, bread and bakery products, cereals and grains, meat products, and dairy products are the most significant contributors to dietary salt [46]. The high salt content of these industrial products may also partly contribute to the appearance of hypertension [47], endothelial dysfunction [22, 48], and, as a consequence, also CVD $[49,50]$.

Moreover, for the industrial production of UPF, vegetable oils (the most used due to their low cost) are hydrogenated. If the hydrogenation is total, saturated fat is formed, but if the hydrogenation is partial, TFAs are also produced. These partially hydrogenated oils are consumed in margarine, fast food, and other UPF such as cakes, rolls, confectionery, biscuits, chocolate, potato chips, and crisps. A relationship between TFA intake and increased risk of CVD has been established [51, 52]. In a meta-analysis of prospective studies, a $2 \%$ increase in total daily energy intake from TFAs was associated with a $23 \%$ increased risk of CVD [53]. In addition, it has been observed that TFAs increase the incorporation of calcium to vascular endothelium cells [54]. Likewise, controlled dietary trials have shown that TFAs have markedly adverse effects on serum lipids [55], raising serum concentrations of LDL cholesterol [56], while also decreasing the serum concentration of HDL cholesterol [57]. TFAs have also shown to rise inflammation 
Table 1 Characteristics of the study participants according to quartiles of energy-adjusted ultra-processed food (UPF) consumption, the AWHS cohort study $(N=1876)$

\begin{tabular}{|c|c|c|c|c|c|}
\hline & \multicolumn{5}{|c|}{ Energy-adjusted UPF consumption (g/day) } \\
\hline & $\mathrm{Q} 1(n=469)$ & Q2 $(n=469)$ & Q3 $(n=469)$ & Q4 $(n=469)$ & $p$ value \\
\hline Energy-adjusted UPF consumption (g/day)* & $117 \pm 56$ & $169 \pm 66$ & $263 \pm 76$ & $484 \pm 217$ & $<.01$ \\
\hline Total energy intake (kcal) & $2988 \pm 564$ & $2685 \pm 616$ & $2793 \pm 638.4$ & $2840 \pm 601$ & $<.01$ \\
\hline Age (years) & $51.5 \pm 3.6$ & $51.3 \pm 3.7$ & $51.0 \pm 3.7$ & $50.7 \pm 3.9$ & $<.01$ \\
\hline Married (\%) & $85.6(406)$ & $85.5(401)$ & 84.9 (398) & $85.3(400)$ & .90 \\
\hline Education (\%) & & & & & .68 \\
\hline Middle school & $52.6(245)$ & $49.1(229)$ & $52.2(242)$ & $55.0(255)$ & \\
\hline High school & $12.0(56)$ & $11.8(55)$ & $10.1(47)$ & $10.1(47)$ & \\
\hline Professional training & $31.8(148)$ & $33.5(156)$ & $34.0(158)$ & $30.6(142)$ & \\
\hline College & $3.6(17)$ & $5.6(26)$ & $3.7(17)$ & $4.3(20)$ & \\
\hline Smoking (\%) & & & & & $<.01$ \\
\hline Never & $20.6(96)$ & $19.7(92)$ & $26.3(123)$ & $25.5(119)$ & \\
\hline Former & $29.2(136)$ & $29.4(137)$ & $34.1(159)$ & $36.2(169)$ & \\
\hline Current & $50.2(234)$ & $50.9(237)$ & $39.6(185)$ & $38.3(179)$ & \\
\hline Physical activity (MET-h/week) & $36.22 \pm 23.8$ & $31.84 \pm 21.0$ & $31.0 \pm 22.1$ & $31.5 \pm 22.5$ & $<.01$ \\
\hline \multicolumn{6}{|l|}{ Sleep duration (hours) } \\
\hline During the week & $6.3 \pm 1.0$ & $6.3 \pm 0.9$ & $6.3 \pm 1.0$ & $6.3 \pm 1.0$ & .66 \\
\hline During the weekend & $7.3 \pm 1.1$ & $7.3 \pm 1.2$ & $7.3 \pm 1.2$ & $7.3 \pm 1.2$ & .92 \\
\hline Body mass index (\%) & & & & & .35 \\
\hline$<25 \mathrm{~kg} / \mathrm{m}^{2}$ & $20.5(96)$ & $17.5(82)$ & $18.8(88)$ & $19.6(92)$ & \\
\hline 25 to $<30 \mathrm{~kg} / \mathrm{m}^{2}$ & $59.9(281)$ & $58.6(275)$ & $57.1(268)$ & $54.6(256)$ & \\
\hline$\geq 30 \mathrm{~kg} / \mathrm{m}^{2}$ & $19.6(92)$ & $23.9(112)$ & $24.1(113)$ & $25.8(121)$ & \\
\hline Cholesterol intake (mg/day) & $456.7 \pm 139.3$ & $440.5 \pm 129.4$ & $461.6 \pm 140.6$ & $460.4 \pm 140.4$ & .07 \\
\hline Total cholesterol in blood (mg/dL) & $223.3 \pm 36.1$ & $222.1 \pm 35.7$ & $223.3 \pm 35.4$ & $220.0 \pm 37.6$ & .46 \\
\hline HDL cholesterol in blood (mg/dL) & $54.1 \pm 11.9$ & $52.4 \pm 10.9$ & $52.7 \pm 11.1$ & $52.0 \pm 11.2$ & .03 \\
\hline \multicolumn{6}{|l|}{ Blood pressure (mmHg) } \\
\hline Systolic & $126.3 \pm 14.3$ & $125.3 \pm 13.9$ & $125.6 \pm 14.8$ & $126.6 \pm 14.1$ & .47 \\
\hline Diastolic & $83.2 \pm 9.6$ & $82.9 \pm 9.5$ & $82.9 \pm 9.6$ & $83.8 \pm 9.1$ & .42 \\
\hline Prevalent diabetes (\%) & $4.5(21)$ & $3.4(16)$ & $4.3(20)$ & $3.8(18)$ & .84 \\
\hline Alcohol consumption (g/day) & $25.2 \pm 22.2$ & $18.8 \pm 17.7$ & $20.1 \pm 20.5$ & $20.6 \pm 18.7$ & $<.01$ \\
\hline Total fiber* (g/day) & $27.2 \pm 7.7$ & $25.2 \pm 7.9$ & $24.3 \pm 7.0$ & $23.2 \pm 6.7$ & $<.01$ \\
\hline Omega 3 non-marine source* (g/day) & $1.6 \pm 0.7$ & $1.6 \pm 0.6$ & $1.6 \pm 0.5$ & $1.5 \pm 0.6$ & 0.08 \\
\hline Omega 3 marine source* (g/day) & $0.73 \pm 0.4$ & $0.71 \pm 0.4$ & $0.67 \pm 0.4$ & $0.63 \pm 0.4$ & $<.01$ \\
\hline Vitamin C* (mg/day) & $180.9 \pm 72.8$ & $184.4 \pm 68.9$ & $177.9 \pm 61.5$ & $178.4 \pm 71.3$ & .45 \\
\hline Vitamin $D^{*}(\mu \mathrm{g} /$ day $)$ & $5.4 \pm 3.3$ & $5.5 \pm 3.0$ & $5.2 \pm 2.8$ & $5.0 \pm 2.7$ & .02 \\
\hline Vitamin $A^{*}(\mu \mathrm{g} /$ day $)$ & $1226.4 \pm 673$ & $1220.6 \pm 554$ & $1272.4 \pm 643$ & $1206.7 \pm 682$ & $<.01$ \\
\hline Vitamin $E^{*}$ (mg/day) & $10.5 \pm 3.6$ & $10.9 \pm 3.2$ & $11.4 \pm 3.8$ & $11.5 \pm 3.7$ & $<.01$ \\
\hline Vitamin B6* (mg/day) & $2.5 \pm 0.5$ & $2.5 \pm 0.5$ & $2.4 \pm 0.4$ & $2.3 \pm 0.5$ & $<.01$ \\
\hline Vitamin B9* (mg/day) & $379.7 \pm 72.6$ & $369.9 \pm 71.0$ & $357.4 \pm 61.6$ & $345.3 \pm 66.6$ & $<.01$ \\
\hline Vitamin B12* (mg/day) & $10.1 \pm 4.4$ & $9.7 \pm 3.4$ & $9.8 \pm 4.1$ & $9.2 \pm 4.0$ & $<.01$ \\
\hline Magnesium* (mg/day) & $429.6 \pm 69.6$ & $426.7 \pm 68.3$ & $415.3 \pm 60.6$ & $407.3 \pm 61.7$ & $<.01$ \\
\hline Calcium* (mg/day) & $1018.9 \pm 323.2$ & $1035.8 \pm 285.1$ & $1019.0 \pm 280.3$ & $1019.9 \pm 304.0$ & .78 \\
\hline Zinc* (mg/day) & $15.5 \pm 2.1$ & $14.9 \pm 2.0$ & $14.5 \pm 1.9$ & $14.3 \pm 1.9$ & $<.01$ \\
\hline
\end{tabular}


Table 1 Characteristics of the study participants according to quartiles of energy-adjusted ultra-processed food (UPF) consumption, the AWHS cohort study $(N=1876)$ (Continued)

\begin{tabular}{llllll}
\hline & \multicolumn{4}{l}{ Energy-adjusted UPF consumption $(\mathrm{g} / \text { day })^{*}$} \\
\cline { 2 - 6 } & $\mathrm{Q} 1(n=469)$ & $\mathrm{Q} 2(n=469)$ & $\mathrm{Q} 3(n=469)$ & $\mathrm{Q} 4(n=469)$ & $p$ value \\
\hline lodine* $^{*} \mu \mathrm{g} /$ day $)$ & $301.3 \pm 195.6$ & $294.7 \pm 151.1$ & $276.2 \pm 147.7$ & $258.9 \pm 156.3$ & $<.01$ \\
Selenium* $(\mu \mathrm{g} /$ day $)$ & $132.7 \pm 27.5$ & $123.0 \pm 25.8$ & $116.8 \pm 25.7$ & $113.1 \pm 26.2$ & $<.01$ \\
\hline
\end{tabular}

Continuous variables are presented as mean \pm standard deviation and categorical variables as percentage (frequency, $n$ )

$p$ value estimates are based on one-way ANOVA (Bonferroni's multiple-comparison test) for variables expressed as mean (standard deviation) or Pearson's $\chi^{2}$ test for variables expressed as percentages

UPF ultra-processed food, $Q$ quartiles

*Energy adjusted by the residual method

markers including C-reactive protein (CRP), interleukin6 (IL-6), and tumor necrosis factor-alpha (TNF- $\alpha$ ) [58]. All these factors contribute independently to the development of atherosclerosis [22]. It should be mentioned, however, that the food industry has made remarkable efforts to reduce TFAs these past few years. Consequently, their presence in current UPF may be small [59].

UPF is also much rich in saturated fatty acids (SFAs) than in monounsaturated fatty acids (MUFAs) or polyunsaturated fatty acids (PUFAs). Higher intake of SFAs from pastries and processed food has been associated with a higher risk of CVD [60]. Likewise, the isocaloric substitution of SFAs or TFAs with MUFAs or PUFAs has been consistently associated with a lower risk of CVD and death, both in cohort studies [61] and in randomized controlled trials [62] .

Refined sugars and sweeteners added in UPF have been described as implicated in the development of CVD [63, 64] and its risk factors, such as hypertension [65], diabetes [66], metabolic syndrome [67], and obesity [64].
Food additives in UPF are of special concern. Some of them, such as sulphites [12] and monosodium glutamate [11], have shown several adverse effects on cardiovascular health in experimental studies on cellular models and animals. Likewise, it has been found that long-term consumption of acesulfame K (non-caloric artificial sweetener) might accelerate atherosclerosis in cellular models [10]. However, among the additives, phosphates deserve special mention [68]. UPFs with high amounts of added phosphates are processed meat, ham, sausages, canned fish, baked goods, cola drinks, and other soft drinks. Phosphorus in inorganic phosphate coming from UPF is very effectively absorbed in the gastrointestinal tract (absorbed by approximately $90 \%$ ) with respect to naturally occurring phosphorus in food (absorbed by 40-60\%) [69]. Phosphate induces vascular calcification both in vitro and in vivo $[13,70]$. The promoted process is not merely the passive precipitation of calcium by phosphate, but rather an active cellular process in which smooth-muscle cells in blood vessels are reprogrammed to become osteoblast-like cells [13]. This alteration also

Table 2 Progression to higher coronary artery calcium score (CACS) categories according to quartiles of ultra-processed food (UPF) consumption, using generalized ordered logistic models, the AWHS cohort study $(N=1876)$

\begin{tabular}{|c|c|c|c|c|c|}
\hline \multirow[t]{2}{*}{ CACS categories } & \multicolumn{5}{|c|}{ Quartiles of energy-adjusted UPF consumption ( $\mathrm{g} /$ day)*, odds ratio ( $95 \%$ confidence intervals) } \\
\hline & Q1 & Q2 & Q3 & Q4 & $p$ trend \\
\hline \multicolumn{6}{|c|}{ From the lowest category to the two highest ${ }^{\dagger}$} \\
\hline Model 1, OR (95\% Cl) & 1 (ref.) & $1.10(0.84,1.44)$ & $1.18(0.90,1.55)$ & $1.15(0.88,1.51)$ & .315 \\
\hline Model 2, OR (95\% Cl) & 1 (ref.) & $1.09(0.83,1.44)$ & $1.19(0.90,1.57)$ & $1.14(0.86,1.51)$ & .382 \\
\hline Model 3, OR (95\% Cl) & 1 (ref.) & $1.09(0.83,1.45)$ & $1.17(0.88,1.56)$ & $1.13(0.85,1.50)$ & .425 \\
\hline \multicolumn{6}{|c|}{ From the two lowest categories to the highest ${ }^{\gamma}$} \\
\hline Model 1, OR (95\% Cl) & 1 (ref.) & $1.39(0.88,2.18)$ & $1.47(0.93,2.31)$ & $1.86(1.20,2.87)$ & .006 \\
\hline Model 2, OR (95\% Cl) & 1 (ref.) & $1.37(0.86,2.19)$ & $1.54(0.96,2.47)$ & $1.96(1.24,3.07)$ & .003 \\
\hline Model 3, OR (95\% Cl) & 1 (ref.) & $1.50(0.93,2.42)$ & $1.56(0.96,2.52)$ & $2.00(1.26,3.16)$ & .005 \\
\hline
\end{tabular}

The generalized ordered logistic model (gologit/partial proportional odds model) allows for the no equality of slopes among categories, being less restrictive and more flexible than the ordinal ordered logistic model (parallel-lines model). OR odds ratio, $\mathrm{Cl}$ confidence interval Model 1: logistic regression model adjusted for age

Model 2: as in model 1 and additionally adjusted for marital status, education, smoking, physical activity, sleep duration during weekdays and during the weekend, alcohol consumption, total fiber intake, cholesterol intake, and total energy intake

Model 3: as in model 2 and additionally adjusted for cardiovascular risk factors: total serum cholesterol, HDL serum cholesterol, systolic and diastolic blood pressure, body mass index, and diabetes

*Energy adjusted by the residual method

'Lowest category: CACS of 0 ; the two highest categories: CACS $>0$ and $<100$ together with CACS $\geq 100$

'Two lowest categories: CACS of 0 together with CACS $>0$ and $<100$; highest category: CACS $\geq 100$ 


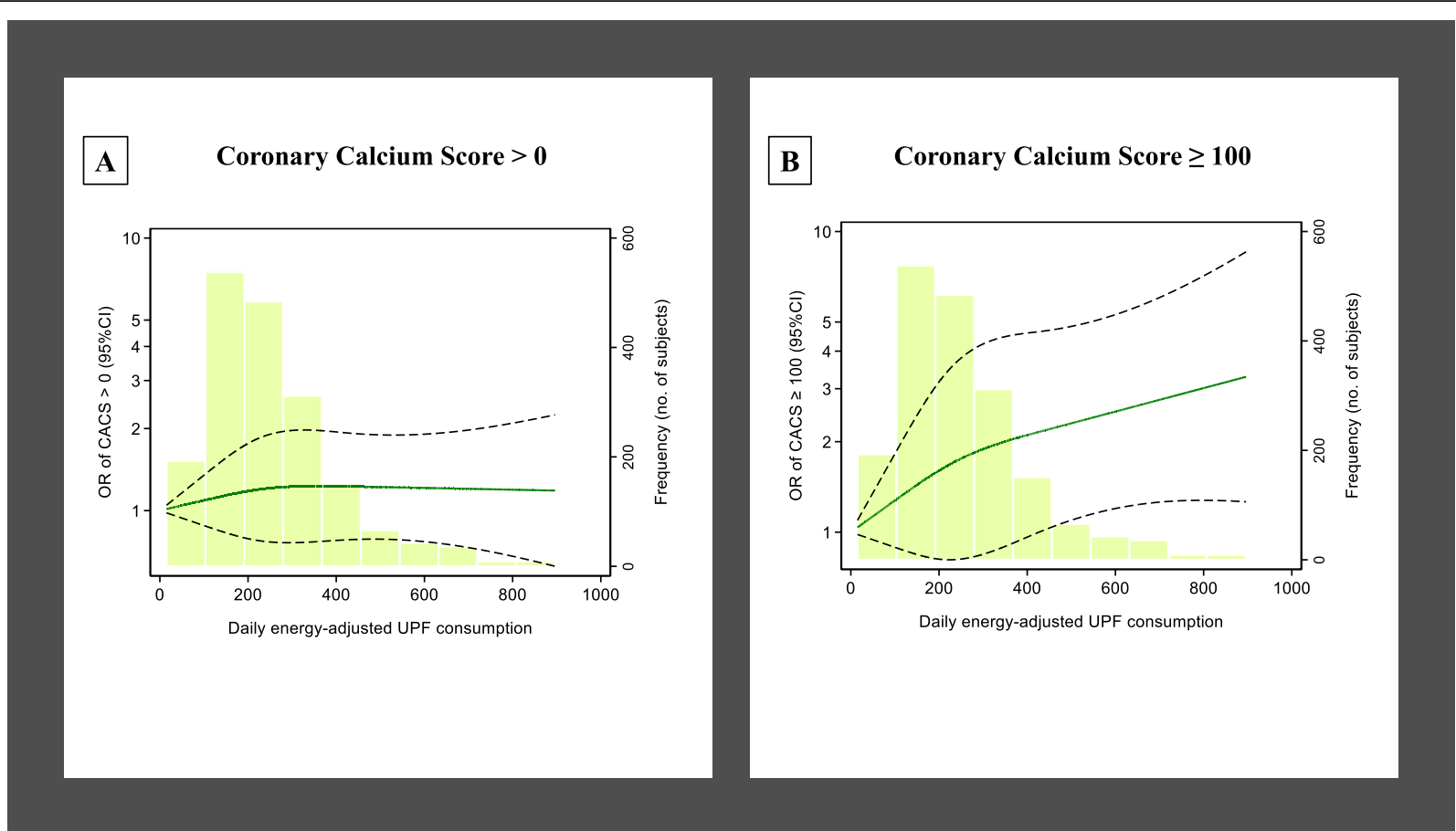

Fig. 2 Restricted cubic splines for the association of Coronary Artery Calcium (CACS) and ultra-processed food (UPF) consumption, in the AWHS cohort study $(N=1876)$. The standard binary logistic regression was used to perform restricted cubic splines with 3 knots of the distribution (at the 10th, 50th, and 90th percentiles of the distribution). Participants with an exposure above the 99th percentile were not included. Dashed lines represent $95 \% \mathrm{Cls}$. The histograms show the distributions of energy-adjusted ultra-processed food consumption. a The odds of CACS $>0$ ( $p$ value of the Wald test for non-linearity is 0.59 ) and $\mathbf{b}$ the odds of CACS > 100 ( $p$ value of the Wald test for non-linearity is 0.029 ) as ultra-processed food consumption increases. Models adjusted for age, marital status, education, smoking, physical activity, sleep duration during weekdays and during the weekend, alcohol consumption, total fiber intake, cholesterol intake, total energy intake, and cardiovascular risk factors: total serum cholesterol, HDL serum cholesterol, systolic and diastolic blood pressure, body mass index, and diabetes. AWHS, Aragon Workers' Health Study; CACS, Coronary Agatston Calcium Score; UPF, ultra-processed food; OR, odds ratio; Cl, confidence interval

seems to occur in the human arteries [71, 72]. Moreover, it has been shown that increased phosphate intake leads to an endothelial-cell function impairment in the vascular system, in both animals and humans [73]. High to normal serum phosphate concentrations are associated with coronary calcification in young healthy men [74] and were found to be a predictor of cardiovascular events in the Framingham study [75].

Neo-formed substances which are produced through packaging, moisture removal, heat treatments, chilling and freezing, acidity control, reaction with chemical additives, and irradiation might also contribute to the harmful effect derived from UPF consumption. An example of a neo-formed substance from packaging is bisphenol A, which has been related to CVD [76]. Likewise, acrylamide, which is produced by heat treatments and found in fried potatoes, biscuits, bread, processed meat, and even coffee, has also been associated with CVD [77, 78].

Further research is needed to identify what specific processes, compounds, or UPF subtypes play an important role in this association found between UPF consumption and increased risk of early atherosclerosis, also taking into account the possibility of synergic effects among the abovementioned mechanisms. This knowledge will allow, in the short term, to recommend a reduction of the consumption of these products and, in the long term, to refine the processes of the food industry with the aim of providing a healthier offer.

Some limitations of our study must be recognized. First, the cross-sectional design of our study prevents us from establishing a causal link between consumption of UPF and subclinical coronary atherosclerosis. However, since calcium in the coronary artery is subclinical, reverse causation is highly unlikely. Also, although we adjust for a wide range of potential confounders, we cannot rule out residual confounding.

Although the FFQ provides an adequate assessment of an individual's usual diet [35], because of its selfreported nature and the potential recall bias, inaccuracies in the exposure assessment cannot be ruled out. Likewise, the FFQ was not designed specifically to collect data on UPF following the methodology of the NOVA classification, which could lead to misclassification. Nonetheless, the applied methodology is the most 
frequently used classification of UPF in epidemiological studies. Despite the NOVA classification being reproducible and easily incorporated into messages and its consequent utility for public health, it is not exempted from controversies $[79,80]$.

We should note that the CACS fails to capture information about the regional distribution of calcification within the coronary tree and does not incorporate information on the number or size of calcified coronary lesions. The limited external validity of our findings should also be mentioned, as the cohort was not representative of the general population.

This study notably presents important strengths, such as its novelty and the quality of the methodology used to collect clinical data and to quantify coronary calcium, which is a measurement with strong published support of its value for clinical risk prediction. Also, the detailed data collection for confounders, including accurate measurements of blood pressure and serum lipids, helps reduce confounding. Finally, another asset is the consistency of the findings after using different statistical approaches to assess the association between UPF and subclinical atherosclerosis.

\section{Conclusion}

In conclusion, in this study of asymptomatic Spanish working men, we found that those consuming the highest amount of UPF had twice as much probability of having subclinical coronary atherosclerosis, regardless of blood lipids, hypertension, BMI, and other cardiovascular risk factors.

\section{Supplementary information}

Table S1 displays the food-items in the AWHS food frequency questionnaire classified as ultra-processed foods according to degree of processing (NOVA group 4). Table S2 Association between Agatston's Coronary Artery Calcium Score and quartiles of UPF consumption by using the standard binary logistic regression. The $=\mathrm{R}(95 \% \mathrm{Cl})$ for CACS $>0$ (compared with CACS score $\leq 0$ ) and for CACS score $\geq 100$ (compared to CACS score $<100$ ) are displayed. Supplementary information accompanies this paper at https://doi.org/10. 1186/s12916-020-01678-8.

Additional file 1: Table S1 Food-items included as UPF; Table S2 UPFCACS association.

\section{Abbreviations \\ AWHS: Aragon Workers' Health Study; BMI: Body mass index; CACS: Agatston's Coronary Artery Calcium Score (CACS); Cl: Confidence interval; CVD: Cardiovascular disease; OR: Odds ratio; UPF: Ultra-processed food}

\section{Acknowledgments}

Our thanks to the Juan de la Cierva post-doctoral scholarship-training awarded to CD-V from the Ministry of Spain.

\section{Authors' contributions}

PG-C conceived the presented idea. CD-V and HMS performed the computations and were the major contributors in writing the manuscript. PG-C and
$M L$ verified the analytical methods and supervised the findings of this work. All authors read and approved the final manuscript.

\section{Funding}

AWHS was funded through a collaboration agreement between the Aragonese Institute of Health Sciences (I+CS) of the Regional Government of Aragon, the National Cardiovascular Research Centre (CNIC) of the Carlos III Health Institute, and Opel Spain. This study was also partially supported by grants: PI17/1709 (Secretary of State for R\&D and ERDF/ESF), and Integrated Projects of Excellence in Health Research Institutes PIE16/00022 (Secretary of State for R\&D and ERDF/ESF), the ATHLOS Project (EU H2020-ID project: 635316), CIBERCV and CIBERESP of the Carlos III Health Institute, Madrid, Spain

\section{Availability of data and materials}

The datasets used and/or analyzed during the current study are available from the corresponding author on reasonable request.

\section{Ethics approval and consent to participate}

The study was approved by the central Institutional Review Board of Aragón (CEICA), the National Center for Cardiovascular Research (CNIC), and the management and employee representatives of General Motors, Spain.

\section{Consent for publication}

Not applicable.

\section{Competing interests}

The authors declare that they have no competing interests.

\section{Author details}

${ }^{1}$ Department of Preventive Medicine and Public Health, School of Medicine, Universidad Autónoma de Madrid, CEI UAM+CSIC, Avda. Arzobispo Morcillo, n 4, 28029 Madrid, Spain. ${ }^{2}$ Unit of Nutritional and Cardiovascular

Epidemiology, Environmental Medicine Institute (IMM), Karolinska Institutet, Stockholm, Sweden. ${ }^{3}$ CIBERESP (CIBER of Epidemiology and Public Health) Instituto de Salud Carlos III, Madrid, Spain. ${ }^{4}$ Instituto de Investigación IdiPaz, Madrid, Spain. ${ }^{5}$ IMDEA-Food Institute CEI UAM+CSIC, Madrid, Spain. ${ }^{6}$ IIS Aragón, Hospital Universitario Miguel Servet, Universidad de Zaragoza, Zaragoza, Spain. ${ }^{7}$ CIBERCV Instituto de Salud Carlos III, Madrid, Spain. ${ }^{8}$ Department of Microbiology, Preventive Medicine and Public Health, University of Zaragoza, Zaragoza, Spain. 'Department of Nutrition, Harvard T.H. Chan School of Public Health, Boston, MA, USA. ${ }^{10}$ Agencia Aragonesa para la Investigación y el Desarrollo (ARAID), Zaragoza, Spain.

Received: 8 May 2020 Accepted: 23 June 2020

Published online: 13 August 2020

References

1. Monteiro CA, Moubarac JC, Cannon G, Ng SW, Popkin B. Ultra-processed products are becoming dominant in the global food system. Obes Rev. 2013:14(Suppl 2):21-8.

2. Blanco-Rojo R, Sandoval-Insausti H, Lopez-Garcia E, Graciani A, Ordovas JM Banegas JR, et al. Consumption of ultra-processed foods and mortality: a national prospective cohort in Spain. Mayo Clin Proc. 2019;94(11):2178-88.

3. Latasa P, Louzada M, Martinez Steele E, Monteiro CA. Added sugars and ultra-processed foods in Spanish households (1990-2010). Eur J Clin Nutr. 2018;72(10):1404-12

4. Slimani N, Deharveng G, Southgate DA, Biessy C, Chajes V, van Bakel MM, et al. Contribution of highly industrially processed foods to the nutrient intakes and patterns of middle-aged populations in the European Prospective Investigation into Cancer and Nutrition study. Eur J Clin Nutr. 2009;63(Suppl 4):S206-25.

5. Food, Nations AOotU. Guidelines on the collection of information on food processing through food consumption surveys. Food and Agriculture Organization of the United Nations Rome; 2015.

6. Monteiro CA, Cannon G, Levy R, Moubarac J-C, Jaime P, Martins AP, et al. NOVA. The star shines bright. 2016;7(1-3):28-38.

7. Merchant AT, Kelemen LE, de Koning L, Lonn E, Vuksan V, Jacobs R, et al. Interrelation of saturated fat, trans fat, alcohol intake, and subclinical atherosclerosis. Am J Clin Nutr. 2008;87(1):168-74. 
8. Yang Q, Zhang Z, Gregg EW, Flanders WD, Merritt R, Hu FB. Added sugar intake and cardiovascular diseases mortality among US adults. JAMA Intern Med. 2014;174(4):516-24.

9. Zhao $X$, Yang $X$, Zhang $X, L i Y$, Zhao $X$, Ren $L$, et al. Dietary salt intake and coronary atherosclerosis in patients with prehypertension. J Clin Hypertens (Greenwich). 2014;16(8):575-80.

10. Jang W, Jeoung NH, Cho KH. Modified apolipoprotein (apo) A-I by artificial sweetener causes severe premature cellular senescence and atherosclerosis with impairment of functional and structural properties of apoA-l in lipidfree and lipid-bound state. Mol Cells. 2011;31(5):461-70.

11. Singh K, Ahluwalia P. Effect of monosodium glutamate on lipid peroxidation and certain antioxidant enzymes in cardiac tissue of alcoholic adult male mice. J Cardiovasc Dis Res. 2012;3(1):12-8.

12. Zhang Q, Bai Y, Yang Z, Tian J, Meng Z. The molecular mechanisms of sodium metabisulfite on the expression of K ATP and L-Ca2+ channels in rat hearts. Regul Toxicol Pharmacol. 2015;72(3):440-6.

13. Giachelli $\mathrm{CM}$. The emerging role of phosphate in vascular calcification. Kidney Int. 2009;75(9):890-7.

14. Srour B, Fezeu LK, Kesse-Guyot E, Alles B, Mejean C, Andrianasolo RM, et al. Ultra-processed food intake and risk of cardiovascular disease: prospective cohort study (NutriNet-Sante). BMJ. 2019:365:11451.

15. Silva Meneguelli T, Viana Hinkelmann J, Hermsdorff HHM, Zulet MA, Martinez JA, Bressan J. Food consumption by degree of processing and cardiometabolic risk: a systematic review. Int J Food Sci Nutr. 2020:1-15.

16. Mendonca RD, Pimenta AM, Gea A, de la Fuente-Arrillaga C, MartinezGonzalez MA, Lopes AC, et al. Ultraprocessed food consumption and risk of overweight and obesity: the University of Navarra Follow-Up (SUN) cohort study. Am J Clin Nutr. 2016;104(5):1433-40.

17. Mendonça RD, Lopes ACS, Pimenta AM, Gea A, Martinez-Gonzalez MA, BesRastrollo M. Ultra-processed food consumption and the incidence of hypertension in a Mediterranean cohort: the Seguimiento Universidad de Navarra Project. Am J Hypertens. 2017;30(4):358-66.

18. Rauber F, Campagnolo PD, Hoffman DJ, Vitolo MR. Consumption of ultraprocessed food products and its effects on children's lipid profiles: a longitudinal study. Nutr Metab Cardiovasc Dis. 2015;25(1):116-22.

19. Srour B, Fezeu LK, Kesse-Guyot E, Alles B, Debras C, Druesne-Pecollo N, et al. Ultraprocessed food consumption and risk of type 2 diabetes among participants of the NutriNet-Sante prospective cohort. JAMA Intern Med. 2019;180(2):283-291.

20. Kim H, Hu EA, Rebholz CM. Ultra-processed food intake and mortality in the USA: results from the Third National Health and Nutrition Examination Survey (NHANES III, 1988-1994). Public Health Nutr. 2019;22(10):1777-85.

21. Rico-Campa A, Martinez-Gonzalez MA, Alvarez-Alvarez I, Mendonca RD, de la Fuente-Arrillaga C, Gomez-Donoso C, et al. Association between consumption of ultra-processed foods and all cause mortality: SUN prospective cohort study. BMJ. 2019;365:11949.

22. Ross R. The pathogenesis of atherosclerosis: a perspective for the 1990s. Nature. 1993;362(6423):801-9.

23. Budoff MJ, Nasir K, McClelland RL, Detrano R, Wong N, Blumenthal RS, et al. Coronary calcium predicts events better with absolute calcium scores than age-sex-race/ethnicity percentiles: MESA (Multi-Ethnic Study of Atherosclerosis). J Am Coll Cardiol. 2009;53(4):345-52.

24. Lo-Kioeng-Shioe MS, Rijlaarsdam-Hermsen D, van Domburg RT, Hadamitzky M, Lima JAC, Hoeks SE, et al. Prognostic value of coronary artery calcium score in symptomatic individuals: a meta-analysis of 34,000 subjects. Int J Cardiol. 2020;299:56-62.

25. Tota-Maharaj R, Blaha MJ, Blankstein R, Silverman MG, Eng J, Shaw LJ, et al. Association of coronary artery calcium and coronary heart disease events in young and elderly participants in the multi-ethnic study of atherosclerosis: a secondary analysis of a prospective, population-based cohort. Mayo Clin Proc. 2014;89(10):1350-9.

26. Blaha MJ, Mortensen MB, Kianoush S, Tota-Maharaj R, Cainzos-Achirica M. Coronary artery calcium scoring: is it time for a change in methodology? JACC Cardiovasc Imaging. 2017;10(8):923-37.

27. Hecht H, Blaha MJ, Berman DS, Nasir K, Budoff M, Leipsic J, et al. Clinical indications for coronary artery calcium scoring in asymptomatic patients: expert consensus statement from the Society of Cardiovascular Computed Tomography. J Cardiovasc Comput Tomogr. 2017;11(2):157-68.

28. Detrano R, Guerci AD, Carr JJ, Bild DE, Burke G, Folsom AR, et al. Coronary calcium as a predictor of coronary events in four racial or ethnic groups. N Engl J Med. 2008;358(13):1336-45.
29. Leening MJ, Elias-Smale SE, Kavousi M, Felix JF, Deckers JW, Vliegenthart R, et al. Coronary calcification and the risk of heart failure in the elderly: the Rotterdam study. JACC Cardiovasc Imaging. 2012;5(9):874-80.

30. Hermann DM, Gronewold J, Lehmann N, Moebus S, Jockel KH, Bauer M, et al. Coronary artery calcification is an independent stroke predictor in the general population. Stroke. 2013;44(4):1008-13.

31. Casasnovas JA, Alcaide V, Civeira F, Guallar E, Ibanez B, Borreguero JJ, et al. Aragon workers' health study--design and cohort description. BMC Cardiovasc Disord. 2012:12:45.

32. Laclaustra M, Casasnovas JA, Fernandez-Ortiz A, Fuster V, Leon-Latre M, Jimenez-Borreguero $\sqcup$, et al. Femoral and carotid subclinical atherosclerosis association with risk factors and coronary calcium: the AWHS study. J Am Coll Cardiol. 2016:67(11):1263-74.

33. Martinez-Gonzalez MA, Lopez-Fontana C, Varo JJ, Sanchez-Villegas A, Martinez JA. Validation of the Spanish version of the physical activity questionnaire used in the Nurses' Health Study and the Health Professionals' Follow-up Study. Public Health Nutr. 2005;8(7):920-7.

34. de la Fuente-Arrillaga C, Ruiz ZV, Bes-Rastrollo M, Sampson L, MartinezGonzalez MA. Reproducibility of an FFQ validated in Spain. Public Health Nutr. 2010;13(9):1364-72.

35. Fernández-Ballart JD, Piñol JL, Zazpe I, Corella D, Carrasco P, Toledo E, et al. Relative validity of a semi-quantitative food-frequency questionnaire in an elderly Mediterranean population of Spain 2010; 103(12):1808-1816.

36. Martin-Moreno JM, Boyle P, Gorgojo L, Maisonneuve P, FernandezRodriguez JC, Salvini S, et al. Development and validation of a food frequency questionnaire in Spain. Int J Epidemiol. 1993;22(3):512-9.

37. Willett W, Stampfer MJ. Total energy intake: implications for epidemiologic analyses. Am J Epidemiol. 1986;124(1):17-27.

38. Agatston AS, Janowitz WR, Hildner FJ, Zusmer NR, Viamonte M Jr, Detrano R. Quantification of coronary artery calcium using ultrafast computed tomography. J Am Coll Cardiol. 1990;15(4):827-32.

39. Erbel R, Mohlenkamp S, Moebus S, Schmermund A, Lehmann N, Stang A, et al. Coronary risk stratification, discrimination, and reclassification improvement based on quantification of subclinical coronary atherosclerosis: the Heinz Nixdorf Recall study. J Am Coll Cardiol. 2010;56(17):1397-406.

40. Williams RJTJOMS. Understanding and interpreting generalized ordered logit models. 2016:40(1):7-20.

41. Ahmed HM, Blaha MJ, Nasir K, Jones SR, Rivera JJ, Agatston A, et al. Low-risk lifestyle, coronary calcium, cardiovascular events, and mortality: results from MESA. Am J Epidemiol. 2013;178(1):12-21.

42. Esposito K, Marfella R, Ciotola M, Di Palo C, Giugliano F, Giugliano G, et al. Effect of a mediterranean-style diet on endothelial dysfunction and markers of vascular inflammation in the metabolic syndrome: a randomized trial. JAMA. 2004;292(12):1440-6.

43. Estruch R, Ros E, Salas-Salvadó J, Covas M-I, Corella D, Arós F, et al. Primary prevention of cardiovascular disease with a Mediterranean diet supplemented with extra-virgin olive oil or nuts 2018;378(25):e34.

44. Waterlander WE, de Haas WE, van Amstel I, Schuit AJ, Twisk JW, Visser M, et al. Energy density, energy costs and income - how are they related? Public Health Nutr. 2010;13(10):1599-608.

45. Benelam B. Satiety and the anorexia of ageing. Br J Community Nurs. 2009; 14(8):332-5.

46. Bhat $\mathrm{S}$, Marklund M, Henry ME, Appel $\amalg$, Croft KD, Neal B, et al. A systematic review of the sources of dietary salt around the world. Advances in nutrition (Bethesda, Md). 2020.

47. Aburto NJ, Ziolkovska A, Hooper L, Elliott P, Cappuccio FP, Meerpohl JJ. Effect of lower sodium intake on health: systematic review and metaanalyses. BMJ. 2013;346:11326.

48. Tzemos N, Lim PO, Wong S, Struthers AD, MacDonald TM. Adverse cardiovascular effects of acute salt loading in young normotensive individuals. Hypertension. 2008;51(6):1525-30.

49. He FJ, MacGregor GA. Role of salt intake in prevention of cardiovascular disease: controversies and challenges. Nat Rev Cardiol. 2018;15(6):371-7.

50. Strazzullo P, D'Elia L, Kandala NB, Cappuccio FP. Salt intake, stroke, and cardiovascular disease: meta-analysis of prospective studies. BMJ. 2009;339: b4567.

51. Oh K, Hu FB, Manson JE, Stampfer MJ, Willett WC. Dietary fat intake and risk of coronary heart disease in women: 20 years of follow-up of the nurses' health study. Am J Epidemiol. 2005;161(7):672-9. 
52. Oomen CM, Ocke MC, Feskens EJ, van Erp-Baart MA, Kok FJ, Kromhout D. Association between trans fatty acid intake and 10-year risk of coronary heart disease in the Zutphen Elderly Study: a prospective population-based study. Lancet (London, England). 2001;357(9258):746-51.

53. Mozaffarian D, Katan MB, Ascherio A, Stampfer MJ, Willett WC. Trans fatty acids and cardiovascular disease. N Engl J Med. 2006:354(15):1601-13.

54. Ballesteros-Vásquez M, Valenzuela-Calvillo L, Artalejo-Ochoa E, Robles-Sardin AE. Ácidos grasos trans: un análisis del efecto de su consumo en la salud humana, regulación del contenido en alimentos y alternativas para disminuirlos. Nutr Hosp. 2012;27(1):54-64.

55. Mensink RP, Zock PL, Kester AD, Katan MB. Effects of dietary fatty acids and carbohydrates on the ratio of serum total to $\mathrm{HDL}$ cholesterol and on serum lipids and apolipoproteins: a meta-analysis of 60 controlled trials. Am J Clin Nutr. 2003;77(5):1146-55

56. Mauger JF, Lichtenstein AH, Ausman LM, Jalbert SM, Jauhiainen M, Ehnholm $C$, et al. Effect of different forms of dietary hydrogenated fats on LDL particle size. Am J Clin Nutr. 2003;78(3):370-5

57. Matthan NR, Welty FK, Barrett PH, Harausz C, Dolnikowski GG, Parks JS, et al. Dietary hydrogenated fat increases high-density lipoprotein apoA-I catabolism and decreases low-density lipoprotein apoB-100 catabolism in hypercholesterolemic women. Arterioscler Thromb Vasc Biol. 2004;24(6):1092-7.

58. Lopez-Garcia E, Schulze MB, Meigs JB, Manson JE, Rifai N, Stampfer MJ, et al. Consumption of trans fatty acids is related to plasma biomarkers of inflammation and endothelial dysfunction. J Nutr. 2005;135(3):562-6.

59. Perez-Farinos N, Dal Re Saavedra MA, Villar Villalba C, Robledo de Dios T. Trans-fatty acid content of food products in Spain in 2015. Gac Sanit 2016 30(5):379-382.

60. Guasch-Ferre M, Babio N, Martinez-Gonzalez MA, Corella D, Ros E, MartinPelaez $\mathrm{S}$, et al. Dietary fat intake and risk of cardiovascular disease and allcause mortality in a population at high risk of cardiovascular disease. Am J Clin Nutr. 2015;102(6):1563-73.

61. Jakobsen MU, O'Reilly EJ, Heitmann BL, Pereira MA, Balter K, Fraser GE, et al. Major types of dietary fat and risk of coronary heart disease: a pooled analysis of 11 cohort studies. Am J Clin Nutr. 2009;89(5):1425-32.

62. Hooper L, Summerbell CD, Thompson R, Sills D, Roberts FG, Moore HJ, et al. Reduced or modified dietary fat for preventing cardiovascular disease. Cochrane Database of Systematic Reviews. Version published: 16 May 2012 Available in: https://doi.org/10.1002/14651858.CD002137.pub3.

63. de Koning L, Malik VS, Kellogg MD, Rimm EB, Willett WC, Hu FB. Sweetened beverage consumption, incident coronary heart disease, and biomarkers of risk in men. Circulation. 2012;125(14):1735-41 S1.

64. Malik VS, Popkin BM, Bray GA, Despres JP, Hu FB. Sugar-sweetened beverages, obesity, type 2 diabetes mellitus, and cardiovascular disease risk. Circulation. 2010;121(11):1356-64.

65. Brown IJ, Stamler J, Van Horn L, Robertson CE, Chan Q, Dyer AR, et al. Sugar-sweetened beverage, sugar intake of individuals, and their blood pressure: international study of macro/micronutrients and blood pressure. Hypertension. 2011;57(4):695-701.

66. Murray I, Kazman S. Sugar-sweetened beverages, weight gain, and diabetes. JAMA. 2005;293(4):422 author reply -3.

67. Martinez Steele E, Juul F, Neri D, Rauber F, Monteiro CA. Dietary share of ultra-processed foods and metabolic syndrome in the US adult population. Prev Med. 2019;125:40-8.

68. Karalis M, Murphy-Gutekunst L. Enhanced foods: hidden phosphorus and sodium in foods commonly eaten. J Ren Nutr. 2006;16(1):79-81.

69. Uribarri J. Phosphorus homeostasis in normal health and in chronic kidney disease patients with special emphasis on dietary phosphorus intake. Semin Dial. 2007;20(4):295-301.

70. Stubbs JR, Liu S, Tang W, Zhou J, Wang Y, Yao X, et al. Role of hyperphosphatemia and 1,25-dihydroxyvitamin D in vascular calcification and mortality in fibroblastic growth factor 23 null mice. J Am Soc Nephrol. 2007;18(7):2116-24.

71. Moe SM, O'Neill KD, Duan D, Ahmed S, Chen NX, Leapman SB, et al. Medial artery calcification in ESRD patients is associated with deposition of bone matrix proteins. Kidney Int. 2002;61(2):638-47.

72. Shroff RC, McNair R, Skepper JN, Figg N, Schurgers $\amalg$, Deanfield J, et al. Chronic mineral dysregulation promotes vascular smooth muscle cell adaptation and extracellular matrix calcification. J Am Soc Nephrol. 2010; 21(1):103-12.
73. Shuto E, Taketani Y, Tanaka R, Harada N, Isshiki M, Sato M, et al. Dietary phosphorus acutely impairs endothelial function. J Am Soc Nephrol. 2009; 20(7):1504-12.

74. Foley RN, Collins AJ, Herzog CA, Ishani A, Kalra PA. Serum phosphorus levels associate with coronary atherosclerosis in young adults. J Am Soc Nephrol. 2009;20(2):397-404.

75. Dhingra R, Sullivan LM, Fox CS, Wang TJ, D'Agostino RB Sr, Gaziano JM, et al. Relations of serum phosphorus and calcium levels to the incidence of cardiovascular disease in the community. Arch Intern Med. 2007;167(9):879-85.

76. Rancière F, Lyons JG, Loh VH, Botton J, Galloway T, Wang T, et al. Bisphenol A and the risk of cardiometabolic disorders: a systematic review with metaanalysis of the epidemiological evidence. Envioron Health. 2015;14(1):46.

77. DeJarnett N, Conklin DJ, Riggs DW, Myers JA, OToole TE, Hamzeh I, et al. Acrolein exposure is associated with increased cardiovascular disease risk. J Am Heart Assoc. 2014;3(4):e000934. https://doi.org/10.1161/JAHA.114. 000934.

78. Zhang Y, Huang M, Zhuang P, Jiao J, Chen X, Wang J, et al. Exposure to acrylamide and the risk of cardiovascular diseases in the National Health and Nutrition Examination Survey 2003-2006. Environ Int. 2018;117:154-63.

79. Gibney MJ, Forde CG, Mullally D, Gibney ER. Ultra-processed foods in human health: a critical appraisal. Am J Clin Nutr. 2017;106(3):717-24.

80. Monteiro CA, Cannon G, Moubarac JC, Levy RB, Louzada MLC, Jaime PC. Ultra-processing. An odd 'appraisal'. Public Health Nutr. 2018;21(3):497-501.

\section{Publisher's Note}

Springer Nature remains neutral with regard to jurisdictional claims in published maps and institutional affiliations.
Ready to submit your research? Choose BMC and benefit from:

- fast, convenient online submission

- thorough peer review by experienced researchers in your field

- rapid publication on acceptance

- support for research data, including large and complex data types

- gold Open Access which fosters wider collaboration and increased citations

- maximum visibility for your research: over $100 \mathrm{M}$ website views per year

At BMC, research is always in progress.

Learn more biomedcentral.com/submissions 